\title{
ERRATA
}

\section{ERRATUM TO: CRYSTAL STRUCTURE AND LUMINESCENT PROPERTY OF A NEW TWO-DIMENSIONAL POLYMER BASED ON 1,4-BIS(4-(IMIDAZOLE-1-YL)BENZYL)PIPERAZINE}

\author{
C. Zhang ${ }^{1}$, J.-Q. Tao ${ }^{1}$, and J. Wang ${ }^{1 *}$
}

Journal of Structural Chemistry, Vol. 60, No. 5, pp. 803-809, October-November, 2018.

DOI: $10.1134 / \mathrm{S} 0022476619070229$

In the original article there was a mistake in the information of the corresponding author. The correct spelling of the names of the authors and their order is: C. Zhang, J.-Q. Tao, and J. Wang*.

The original article can be found online at https://doi.org/10.1134/S0022476619050135.

${ }^{\mathbf{1}}$ School of Chemistry and Environmental Engineering, Yancheng Teachers University, Yancheng, P. R. China; *wjyctu@hotmail.com. 